\title{
VELOCIDADE DE HIDRATAÇÃO EM FUNÇÃO DE CARACTERÍSTICAS DO TEGUMENTO DE SEMENTES DE SOJA DE DIFERENTES CULTIVARES E LOCALIDADES ${ }^{1}$
}

\author{
CLÁUDIO CAVARIANI ${ }^{2}$, MARIANA ZAMPAR TOLEDO ${ }^{3}$, ROBERTO ANTONIO RODELLA ${ }^{4}$, \\ JOSÉ DE BARROS FRANÇA NETO ${ }^{5}$, JOÃO NAKAGAWA ${ }^{6}$
}

\begin{abstract}
RESUMO - A velocidade de hidratação de sementes de soja pode ser afetada pela permeabilidade do tegumento devido a variações de espessura e composição. O objetivo no presente trabalho foi avaliar a relação entre a velocidade de hidratação e a espessura e o teor de lignina do tegumento de sementes de soja de diferentes cultivares e locais de produção. Sementes de soja de diferentes cultivares e localidades de produção, caracterizadas inicialmente quanto ao teor de água, massa de cem sementes, dano mecânico, germinação e condutividade elétrica, foram avaliadas quanto à velocidade de hidratação, ao teor de lignina do tegumento e às espessuras da camada paliçádica, hipoderme, parênquima lacunoso e total deste tecido de cobertura. $\mathrm{O}$ delineamento experimental foi o inteiramente casualizado e as médias foram comparadas pelo teste Tukey $(\mathrm{P} \leq 0,05)$ e pelo teste de correlação linear simples (r). A velocidade de hidratação foi avaliada em esquema fatorial 4 x 8 (cultivar x tempo de hidratação), para cada localidade de produção, ajustando-se curvas de respostas. Concluiu-se que a velocidade de hidratação de sementes de soja é afetada pela cultivar e local de produção e que se relaciona significativamente com a espessura do parênquima lacunoso.
\end{abstract}

Termos para indexação: Glycine max, teor de lignina, espessura do tegumento, absorção de água

\section{SPEED OF HYDRATION AS AFFECTED BY SEED COAT CHARACTERISTICS IN SOYBEAN OF DIFFERENT CULTIVARS AND LOCATIONS}

\begin{abstract}
Hydration speed in soybean seeds can be affected by seed coat permeability due to thickness and composition variations. The objective of the present research was to evaluate the relation between the hydration speed and seed coat thickness and lignin content in soybean of different cultivars and locations of production. Soybean seeds of four cultivars and four production locations, with their moisture content, weight of 100 seeds, mechanical damage, germination and electrical conductivity previously determined, were evaluated by their hydration speed and seed coat characteristics, that consisted of lignin content and the palisade layer, hypodermic layer, lacunary parenchyma and total thickness. A randomized complete design was used and the means were compared by the Tukey test $(\mathrm{P} \leq 0.05)$ and by the simple linear correlation test $(\mathrm{r})$. The hydration speed was evaluated as a factorial arrangement $4 \times 8$ (cultivar $\mathrm{x}$ time of hydration) for each production location and equations were fitted. It was concluded that the hydration speed in soybean seeds was affected by cultivar and production location and that it is correlated significantly to the lacunary parenchyma thickness.
\end{abstract}

Index terms: Glycine max, lignin content, seed coat thickness, water uptake

\footnotetext{
${ }^{1}$ Submetido em 13/03/2008. Aceito para publicação em 20/08/2008. Parte da Dissertação de Mestrado do segundo autor apresentada à Faculdade de Ciências Agronômicas, FCA/UNESP

${ }^{2}$ Eng. Agr. Dr. Professor Assistente, Departamento de Produção Vegetal, FCA/UNESP, Caixa Postal 237, 18610-307. Botucatu, ccavariani@fca. unesp.br

${ }^{3}$ Eng. Agr., Pós graduanda, Departamento de Produção Vegetal, FCA/ UNESP, mztoledo@fca.unesp.br
}

${ }^{4}$ Eng. Agr. Dr., Professor Assistente, Departamento de Botânica, IBB/ UNESP, Distrito de Rubião Jr., s/nº, 18618-000. Botucatu, rodella@ibb. unesp.br

${ }^{5}$ Eng. Agr., Ph.D., Pesquisador Embrapa Soja, Caixa Postal 231, 86001970. Londrina, jbfranca@cnpso.embrapa.br

${ }^{6}$ Eng. Agr., Professor Titular Aposentado, Voluntário, Departamento de Produção Vegetal, FCA/UNESP, secdamv@fca.unesp.br 


\section{INTRODUÇÃO}

A absorção de água é essencial para a retomada de atividades metabólicas de sementes ortodoxas após a maturidade e, portanto, desempenha papel fundamental no processo de germinação. A velocidade na qual a água é absorvida pela semente é influenciada quando há modificação das condições de ambiente, mas a quantidade máxima de água absorvida não se altera, pois é uma propriedade dos colóides hidrofílicos da semente, condicionada pela maturação e/ou pelo armazenamento (Labouriau, 1983).

De acordo com Vertucci (1989), a velocidade de penetração de água é controlada basicamente pelo teor de água na semente, temperatura ambiente e taxa de absorção de água. Este fator não depende apenas do ambiente e inclui características intrínsecas da semente, provavelmente relacionadas à qualidade fisiológica. Também, Popinigis (1985) fez referência aos fatores que condicionam a velocidade de absorção de água, dentre eles as características morfológicas e composição química do tegumento.

O tegumento das sementes exerce papel importante no processo de germinação, pois é um fator regulador do processo de absorção de água (McDonald et al., 1988a). Quando permite a entrada de água na semente, algumas características morfológicas do tegumento podem influenciar o tempo de penetração da água pela interferência exercida no mecanismo de controle de troca de umidade (Costa et al., 1994). McDonald et al. (1988b) constataram, em soja, atenuação, pelo tecido de cobertura, da regulação da passagem de água durante as primeiras oito horas do processo de embebição; após este período, o tegumento torna-se totalmente permeável e pode, inclusive, servir como reservatório de água para uso do eixo embrionário.

A diversidade de características do tegumento de sementes existente nos diferentes genótipos sugere influência deste fator nos resultados de testes qualitativos relacionados à composição e permeabilidade das membranas (Vieira et al., 1996).

Existem indicativos de diferenças na condutividade elétrica entre cultivares de soja estarem relacionadas a variações no conteúdo de lignina no tegumento das sementes (Panobianco et al., 1999). Este conteúdo, que influencia o grau de resistência a danos mecânicos, indica que a alta lignificação do tegumento torna difícil o processo de absorção de água e a perda de substâncias que podem ser lixiviadas da semente (Alvarez, 1994).

Diferenças no teor de lignina entre genótipos de soja, avaliadas pelo teste de condutividade elétrica, foram observadas por Alvarez (1994). Também Panobianco et al. (1999), estudando fatores que afetam a condutividade elétrica em sementes de soja, concluiu ser o genótipo de soja fator influenciador da interpretação dos resultados deste teste, em função do teor de lignina no tegumento da semente. Por sua vez, não está devidamente esclarecida a existência de correlação entre o teor de lignina e a espessura da testa (Tavares et al., 1987).

A espessura da testa de sementes apresenta variações entre espécies e entre cultivares em uma mesma espécie. Esta característica física é uniforme em sementes de uma mesma espécie ou cultivar e tem controle genético. Maior espessura em alguns genótipos contribui com a impermeabilidade do tegumento, sendo que a água tem maior distância a percorrer. Assim, a absorção lenta de água pela testa provoca hidratação lenta das estruturas cotiledonares. Segundo Caviness \& Simpson (1974), a espessura do tegumento das sementes de soja varia de 70 a $100 \mu \mathrm{m}$.

McDonald et al. (1988b) afirmaram, considerando que as sementes absorvem aproximadamente $80 \%$ de água nas primeiras três horas, que a espessura do tegumento da semente é um fator relevante. Em sementes de soja sob condições de absorção mais lenta de água, o tegumento inicialmente retarda a penetração, mas gradualmente facilita o movimento da água até o embrião, permitindo que ambos os cotilédones se hidratem de maneira uniforme. Desta maneira, o tegumento influencia o processo de absorção de água nos estádios iniciais da germinação e contribui para a manutenção do teor de água adequado (McDonald et al., 1988a, b).

O objetivo no presente trabalho foi avaliar a relação entre a velocidade de hidratação e a espessura e o teor de lignina de sementes de soja de diferentes cultivares e locais de produção.

\section{MATERIAL E MÉTODOS}

As sementes de quatro cultivares de soja de ciclo semiprecoce (Embrapa 48, BRS 184, BRS 232 e BRS 245RR), produzidas e beneficiadas em quatro diferentes localidades (Ponta Grossa-PR, Londrina-PR, Mauá da Serra-PR e Orlândia-SP), na safra 2005/2006, foram cedidas pela Embrapa SNT-EN.LDB (Embrapa Serviços de Negócios para Transferência de Tecnologia - Escritório de Negócios de Londrina), situada em Londrina-PR. O manejo adotado durante o processo de produção nas diferentes localidades foi semelhante e, portanto, não influenciou nos resultados obtidos. Assim, é possível afirmar que somente houve efeito dos tratamentos avaliados.

Para uniformizar o tamanho das sementes, com o objetivo de eliminar o efeito desta característica nas avaliações da qualidade fisiológica, as sementes dos diferentes tratamentos foram classificadas mediante agitação em peneiras manuais de crivos oblongos, sendo descartadas aquelas que passaram 
pela peneira 14/64"'x 3/4"' (5,556 x 19,050mm). (BECKERT et al., 2000).

As sementes, acondicionadas em embalagens de papel multifoliado, foram transportadas para o Laboratório de Análise de Sementes do Departamento de Produção Vegetal - Agricultura, Faculdade de Ciências Agronômicas, campus de Botucatu-SP, Universidade Estadual Paulista "Júlio de Mesquita Filho", onde foram mantidas sob condição de ambiente natural (sem controle da temperatura e da umidade relativa do ar).

Na Tabela 1 constam os dados referentes ao teor de água, massa de cem sementes, dano mecânico, germinação e condutividade elétrica das sementes de soja, determinados imediatamente após a chegada do material em Botucatu-SP, em maio de 2006, para caracterização dos lotes. Os referidos testes foram conduzidos como se segue:

TABELA 1. Dados de teor de água, massa de cem sementes, dano mecânico, germinação e condutividade elétrica de sementes de soja em função da cultivar e local de produção.

\begin{tabular}{|c|c|c|c|c|c|c|}
\hline \multirow{2}{*}{ Avaliação } & \multirow{2}{*}{ Localidades } & \multicolumn{4}{|c|}{ Cultivares } & \multirow[b]{2}{*}{ Média } \\
\hline & & Embrapa 48 & BRS 184 & BRS 232 & BRS 245RR & \\
\hline \multirow{5}{*}{$\begin{array}{l}\text { Teor de água } \\
\qquad(\%)\end{array}$} & Mauá da Serra & 10,19 & 8,49 & 8,99 & 8,95 & - \\
\hline & Londrina & 9,98 & 7,89 & 8,24 & 7,35 & - \\
\hline & Ponta Grossa & 7,24 & 7,59 & 8,09 & 8,99 & - \\
\hline & Orlândia & 10,99 & 10,21 & 11,21 & 11,01 & - \\
\hline & Média & - & - & - & - & - \\
\hline \multirow{5}{*}{$\begin{array}{l}\text { Massa de } 100 \\
\text { sementes } \\
(\mathrm{g})\end{array}$} & Mauá da Serra & $18,18 \mathrm{aB}^{1}$ & $18,56 \mathrm{aB}$ & $19,75 \mathrm{aA}$ & $16,85 \mathrm{aC}$ & 18,41 \\
\hline & Londrina & $13,65 \mathrm{cB}$ & $14,79 \mathrm{cA}$ & $15,30 \mathrm{cA}$ & $14,40 \mathrm{cB}$ & 14,53 \\
\hline & Ponta Grossa & $15,07 \mathrm{bD}$ & $17,44 \mathrm{bB}$ & $19,75 \mathrm{aA}$ & $16,40 \mathrm{bC}$ & 17,09 \\
\hline & Orlândia & $13,66 \mathrm{cB}$ & $13,91 \mathrm{~dB}$ & $17,53 \mathrm{bA}$ & $12,32 \mathrm{dC}$ & 14,44 \\
\hline & Média & 15,22 & 16,19 & 18,06 & 15,00 & - \\
\hline \multirow{5}{*}{$\begin{array}{c}\text { Dano } \\
\text { mecânico } \\
(\%)\end{array}$} & Mauá da Serra & $9,0 \mathrm{aA}$ & $9,5 \mathrm{bA}$ & $9,0 \mathrm{bA}$ & $9,5 \mathrm{aA}$ & 9,3 \\
\hline & Londrina & $8,0 \mathrm{aAB}$ & $11,0 \mathrm{bB}$ & $6,0 \mathrm{abAB}$ & $5,0 \mathrm{aA}$ & 7,5 \\
\hline & Ponta Grossa & $10,0 \mathrm{aB}$ & $9,5 \mathrm{bB}$ & $2,5 \mathrm{aA}$ & $6,5 \mathrm{aAB}$ & 7,1 \\
\hline & Orlândia & $8,5 \mathrm{aB}$ & $3,5 \mathrm{aAB}$ & $3,0 \mathrm{aA}$ & $6,5 \mathrm{aAB}$ & 5,4 \\
\hline & Média & 8,9 & 8,4 & 5,1 & 6,9 & - \\
\hline \multirow{5}{*}{$\begin{array}{c}\text { Germinação } \\
(\%)\end{array}$} & Mauá da Serra & $72 \mathrm{aB}$ & $81 \mathrm{aAB}$ & $76 \mathrm{aB}$ & $94 \mathrm{aA}$ & 81 \\
\hline & Londrina & $62 \mathrm{aB}$ & $89 \mathrm{aA}$ & $57 \mathrm{bB}$ & $91 \mathrm{aA}$ & 75 \\
\hline & Ponta Grossa & $66 \mathrm{aBC}$ & $55 \mathrm{bC}$ & $81 \mathrm{aAB}$ & $92 \mathrm{aA}$ & 74 \\
\hline & Orlândia & $69 \mathrm{aAB}$ & $80 \mathrm{aA}$ & $54 \mathrm{bB}$ & $69 \mathrm{bAB}$ & 68 \\
\hline & Média & 67 & 76 & 67 & 86 & - \\
\hline \multirow{5}{*}{$\begin{array}{c}\text { Condutividade } \\
\text { elétrica } \\
\left(\mu \mathrm{S} . \mathrm{cm}^{-1} \cdot \mathrm{g}^{-1}\right)\end{array}$} & Mauá da Serra & 115,85 bA & $107,11 \mathrm{bA}$ & $97,52 \mathrm{bA}$ & $103,06 \mathrm{aA}$ & 105,87 \\
\hline & Londrina & $152,53 \mathrm{cB}$ & $134,27 \mathrm{cB}$ & $107,64 \mathrm{bA}$ & $107,09 \mathrm{aA}$ & 125,38 \\
\hline & Ponta Grossa & 108,18 bA & $157,89 \mathrm{~dB}$ & $99,08 \mathrm{bA}$ & $112,13 \mathrm{aA}$ & 119,32 \\
\hline & Orlândia & 83,49 aAB & 83,73 aAB & $73,41 \mathrm{aA}$ & $96,31 \mathrm{aB}$ & 84,23 \\
\hline & Média & 115,01 & 120,75 & 94,41 & 104,65 & - \\
\hline
\end{tabular}

1 Médias seguidas da mesma letra minúscula na coluna e maiúscula na linha não diferem estatisticamente entre si pelo teste de Tukey $(\mathrm{P} \leq 0,05)$

$\underline{2}$ Dados transformados em arc sen $\sqrt{ }(\mathrm{x} / 100)+0,5$

a) Teor de água: foram empregadas duas repetições de 20 sementes e o método da estufa elétrica de desidratação, sem ventilação forçada, a $105 \pm 3^{\circ} \mathrm{C}$ durante 24 horas (BRASIL, 1992). 
b) Massa de cem sementes: oito repetições de 100 sementes por tratamento foram contadas e tiveram suas massas determinadas, conforme adaptação de instruções contidas em Brasil (1992).

c) Dano mecânico: realizada de acordo com Krzyzanowski et al. (2004), quatro repetições de 50 sementes por tratamento foram imersas durante 10 minutos numa solução diluída de hipoclorito de sódio, concentração de $0,2 \%$. Posteriormente, após eliminação do excesso da solução, foi determinado o número de sementes intumescidas (danificadas). Os resultados foram expressos em porcentagem média por amostra.

d) Germinação: foi instalado com quatro repetições de 50 sementes por tratamento, que foram dispostas em rolos de papel toalha, umedecidos com água destilada em quantidade correspondente a 2,5 vezes a massa do papel seco. Os rolos confeccionados permaneceram acondicionados dentro de sacos plásticos, e então levados para um germinador à temperatura alternada $20-30^{\circ} \mathrm{C}$ por 8 dias. A avaliação constou de duas contagens, aos 5 e aos 8 dias, de acordo com os critérios estabelecidos por Brasil (1992).

e) Condutividade elétrica: consistiu da disposição de quatro repetições de 50 sementes para cada tratamento, com massas conhecidas, em recipientes plásticos, adicionandose $75 \mathrm{~mL}$ de água destilada. Os recipientes foram mantidos em germinador regulado a $25^{\circ} \mathrm{C}$ por 24 horas para, a seguir, proceder-se leitura com condutivímetro (Vieira \& Krzyzanowski, 1999). O resultado foi obtido em $\mu \mathrm{S} \mathrm{cm}^{-1} \mathrm{~g}^{-1}$, dividindo-se a leitura verificada pela massa das sementes.

As avaliações de velocidade de hidratação e de características do tegumento constaram dos testes discriminados a seguir:

f) Espessura do tegumento das sementes: três sementes de cada tratamento, após seccionadas transversalmente, foram embebidas em glicerina pura por aproximadamente 24 horas para amolecimento dos tecidos esclerificados do tegumento (Arantes et al., 1994; Giurizatto et al., 2003). As sementes foram então transferidas para uma solução fixadora e para uma sucessão de soluções de álcool etílico com diluições gradativas (70\%, 90\%, 95\%, 99\% e álcool absoluto, respectivamente) para eliminar a água presente e, concomitantemente, evitar o rompimento dos tecidos. As amostras foram infiltradas com historresina (Gerrits, 1991), seccionadas transversalmente com micrótomo rotatório com $8 \mu \mathrm{m}$ de espessura, coradas com azul de toluidina $0,05 \%$ (O’Brien et al., 1964) e montadas entre lâminas e lamínulas em resina sintética. As espessuras da camada paliçádica, da hipoderme, do parênquima lacunoso e total do tegumento foram determinadas na região mediana do tegumento, entre o hilo e a extremidade oposta, por meio de mesa digitalizadora usando-se um programa computacional específico (Souza et al., 2005), sendo expressas em $\mu \mathrm{m}$.

g) Teor de lignina do tegumento das sementes: o procedimento consistiu em dispor, inicialmente, sementes de cada tratamento imersas em água até que fosse possível separar o tegumento dos cotilédones. Posteriormente, os tegumentos foram mantidos em estufa a $80^{\circ} \mathrm{C}$ até atingirem massa constante e resfriados em um dessecador. Duas repetições de $0,3 \mathrm{~g}$ de tegumento por tratamento, previamente moídos, foram utilizadas para determinação da porcentagem de lignina, conforme descrito por Van Soest \& Wine (1968).

h) Velocidade de hidratação das sementes: a avaliação considerou metodologia descrita por Vieira et al. (1982), com modificação no número de sementes em cada amostra, de 100 para 50 sementes, como proposto por Costa et al. (2002). A hidratação foi conduzida colocando-se as sementes sobre tela suspensa no interior de caixas plásticas de $11 \mathrm{x}$ 11 x 3,5 cm ("gerbox"), normalmente utilizadas no teste de envelhecimento acelerado, contendo $40 \mathrm{~mL}$ de água no fundo. As caixas foram colocadas em germinador regulado a $20^{\circ} \mathrm{C}$, determinando-se as massas das sementes, em intervalos de uma hora, até oito horas após o início do processo. Foram calculados, a seguir, os teores de água atingidos pelas sementes em cada momento, a partir da massa final obtida e teor de água inicial das sementes anteriormente à instalação do teste. Ao final da análise, de acordo com adaptação de Nakagawa et al. (2007), determinou-se o índice de velocidade de hidratação (IVH), baseando-se na fórmula do índice de velocidade de germinação (IVG), de Maguire (1962), com a substituição do dado de germinação pelo de quantidade de água absorvida. Também foram avaliados os acréscimos no teor de água das sementes em cada hora de hidratação, para comparação dos dezesseis tratamentos em estudo.

O delineamento experimental utilizado foi o inteiramente casualizado, com duas repetições para a determinação do teor de lignina, três repetições para determinação da espessura do tegumento e quatro repetições para a avaliação da velocidade de hidratação. Após a obtenção dos dados, foram realizadas análises de variância para as características avaliadas, com comparações das médias através do teste de Tukey a 5\% de probabilidade. Adicionalmente, a velocidade de hidratação foi avaliada em um esquema fatorial 4 x 8 (cultivar x tempo de hidratação), separadamente para cada local de produção, e foram ajustadas curvas de respostas, escolhendo-se a significativa de maior coeficiente de determinação $\left(\mathrm{R}^{2}\right)$. Os dados de caracterização inicial dos materiais e aqueles 
posteriormente obtidos foram submetidos ao teste de correlação linear simples (r).

\section{RESULTADOS E DISCUSSÃO}

Conforme a Tabela 2, o teor de lignina não foi influenciado pelos fatores avaliados ou interação entre ambos; os valores foram próximos aos encontrados em National Research Council (2001), que cita 2,5\% deste componente no tegumento das sementes de soja. Santos et al. (2007) verificaram variações no conteúdo de lignina em sementes de soja com colorações distintas do tegumento, porém sem variações entre cultivares.

TABELA 2. Teor de lignina, espessuras da camada paliçádica, hipoderme, parênquima lacunoso e total do tegumento e índice de velocidade de hidratação de sementes de soja de diferentes cultivares e locais de produção.

\begin{tabular}{|c|c|c|c|c|c|c|}
\hline \multirow{2}{*}{ Avaliação } & \multirow{2}{*}{ Localidades } & \multicolumn{4}{|c|}{ Cultivares } & \multirow[b]{2}{*}{ Média } \\
\hline & & Embrapa 48 & BRS 184 & BRS 232 & BRS 245RR & \\
\hline \multirow{5}{*}{$\begin{array}{c}\text { Teor de } \\
\text { lignina } \\
(\%)\end{array}$} & Mauá da Serra & 2,02 & 1,91 & 1,99 & 2,22 & 2,03 \\
\hline & Londrina & 1,89 & 2,08 & 2,16 & 1,99 & 2,03 \\
\hline & Ponta Grossa & 1,94 & 1,88 & 1,85 & 2,22 & 1,97 \\
\hline & Orlândia & 1,93 & 1,95 & 2,06 & 2,02 & 1,99 \\
\hline & Média & 1,94 & 1,95 & 2,01 & 2,11 & - \\
\hline \multirow{5}{*}{$\begin{array}{l}\text { Camada } \\
\text { paliçádica } \\
(\mu \mathrm{m})\end{array}$} & Mauá da Serra & 42,25 & 41,25 & 41,86 & 46,27 & 42,91 \\
\hline & Londrina & 49,61 & 39,76 & 45,58 & 45,72 & 45,17 \\
\hline & Ponta Grossa & 41,28 & 39,98 & 45,89 & 46,30 & 43,36 \\
\hline & Orlândia & 43,86 & 40,73 & 46,34 & 40,55 & 42,87 \\
\hline & Média & 44,25 & 40,43 & 44,92 & 44,71 & - \\
\hline \multirow{5}{*}{$\begin{array}{l}\text { Hipoderme } \\
\qquad(\mu \mathrm{m})\end{array}$} & Mauá da Serra & 49,90 & 48,87 & 46,47 & 45,48 & 47,68 \\
\hline & Londrina & 54,04 & 55,65 & 55,57 & 48,28 & 53,39 \\
\hline & Ponta Grossa & 43,56 & 44,66 & 45,22 & 56,01 & 47,36 \\
\hline & Orlândia & 45,80 & 54,97 & 54,16 & 46,71 & 50,41 \\
\hline & Média & 48,33 & 51,04 & 50,36 & 49,12 & - \\
\hline \multirow{5}{*}{$\begin{array}{l}\text { Parênquima } \\
\text { lacunoso } \\
(\mu \mathrm{m})\end{array}$} & Mauá da Serra & 15,29 & 16,03 & 15,33 & 14,37 & 15,26 \\
\hline & Londrina & 17,60 & 14,80 & 16,52 & 12,73 & 15,41 \\
\hline & Ponta Grossa & 14,50 & 12,90 & 18,15 & 14,60 & 15,04 \\
\hline & Orlândia & 15,74 & 14,97 & 18,19 & 15,54 & 16,11 \\
\hline & Média & $15,78 \mathrm{AB}^{1}$ & $14,68 \mathrm{AB}$ & $17,05 \mathrm{~A}$ & $14,31 \mathrm{~B}$ & - \\
\hline \multirow{5}{*}{$\begin{array}{l}\text { Espessura } \\
\text { total } \\
(\mu \mathrm{m})\end{array}$} & Mauá da Serra & 107,44 & 106,16 & 103,68 & 106,12 & 105,85 \\
\hline & Londrina & 121,26 & 110,21 & 117,67 & 106,72 & 113,97 \\
\hline & Ponta Grossa & 99,34 & 97,54 & 109,26 & 116,92 & 105,77 \\
\hline & Orlândia & 105,40 & 110,66 & 118,68 & 102,79 & 109,38 \\
\hline & Média & 108,36 & 106,14 & 112,32 & 108,14 & - \\
\hline \multirow{5}{*}{$\begin{array}{c}\text { Índice de } \\
\text { velocidade de } \\
\text { hidratação }\end{array}$} & Mauá da Serra & 0,292 & 0,316 & 0,263 & 0,291 & $0,290 \mathrm{c}$ \\
\hline & Londrina & 0,259 & 0,263 & 0,249 & 0,277 & $0,262 \mathrm{ab}$ \\
\hline & Ponta Grossa & 0,275 & 0,318 & 0,260 & 0,284 & $0,284 \mathrm{bc}$ \\
\hline & Orlândia & 0,264 & 0,239 & 0,235 & 0,237 & $0,244 \mathrm{a}$ \\
\hline & Média & $0,272 \mathrm{AB}$ & $0,284 \mathrm{~B}$ & $0,252 \mathrm{~A}$ & $0,272 \mathrm{AB}$ & - \\
\hline
\end{tabular}

1 Médias seguidas da mesma letra minúscula na coluna e maiúscula na linha não diferem estatisticamente entre si pelo teste de Tukey (P $\leq 0,05)$ 
O corte transversal do tegumento de sementes de soja possibilitou a distinção de quatro camadas: cutícula, epiderme (células paliçádicas ou macroesclereídeos), hipoderme (células em ampulheta, ou células pilares ou osteoesclereídeos) e células parenquimáticas (SWANSON et al., 1985). Cada uma delas difere em número camadas de células e em espessura (PEREIRA \& ANDREWS, 1985; NOODÉN et al., 1985). No presente trabalho, a espessura do tegumento das sementes de soja constou da determinação das medidas das três camadas mais internas do tegumento, ou seja, a camada paliçádica, a hipoderme e o parênquima lacunoso.

De acordo com a Tabela 2, referente às análises das espessuras da camada paliçádica, da hipoderme e total do tegumento das sementes de soja, não foram constatadas significâncias dos fatores estudados ou da interação entre eles, não sendo possível destacar, portanto, tratamentos estatisticamente diferentes em quaisquer combinações. Diferentemente, Arantes et al. (1994) e Giurizatto et al. (2003) constataram diferenças de espessura entre tegumentos de cultivares de soja, considerando as referidas camadas de células. Silva (2003), em avaliação da camada paliçádica do tegumento de sementes de duas cultivares de soja, observou valores médios de espessura próximos aos constatados neste trabalho. Quanto à hipoderme, Duangpatra (1976) observou variação na espessura desta camada de células de 30 a $70 \mu \mathrm{m}$ dependendo da cultivar; os valores de espessura encontrados são coincidentes ao citado intervalo. Também Silva (2003) observou os valores referenciados em avaliação da hipoderme de dois cultivares de soja.

Entretanto, considerando-se a espessura do parênquima lacunoso, observou-se efeito significativo de cultivares (Tabela 2). Esta camada de células é amorfa e encontra-se abaixo dos osteoesclereídeos (SILVA, 2003). Também Silva (2003) constatou diferentes valores de espessura para duas cultivares de soja avaliadas. Os tegumentos das sementes de soja com parênquimas mais e menos espessos foram os das cultivares BRS 232 e BRS 245RR, respectivamente; valores intermediários foram constatados em tegumentos das sementes das cultivares Embrapa 48 e BRS 184, sem diferença estatística entre eles, além de não diferirem dos das demais cultivares.

A análise dos dados do índice de velocidade de hidratação (Tabela 2) indicou efeitos isolados do local de produção e da cultivar. Assim, as sementes oriundas de Mauá da Serra e de Ponta Grossa tiveram valores superiores aos das produzidas em Londrina e em Orlândia. Para as cultivares, sementes do genótipo BRS 184 tiveram maior índice, não diferindo dos valores obtidos com as cultivares Embrapa 48 e BRS 245RR; estas, por sua vez, não diferiram da cultivar BRS 232, cujas sementes tiveram menor índice. A existência de diferença na velocidade de absorção de água por diferentes cultivares de soja foi assinalada por Costa et al. (2002) sem, contudo, precisar a característica distinta entre elas que torna suas sementes mais ou menos permeáveis à água.

Conforme o teste de correlação linear simples, os dados de condutividade elétrica correlacionaram-se significativamente com os de dano mecânico e de índice de velocidade de hidratação, assim como os dois últimos entre si. Loeffler et al. (1988) relataram possível influência de sementes danificadas mecanicamente nos resultados de condutividade elétrica. Desta maneira, é esperada a absorção mais rápida de água por sementes que apresentam rachaduras e trincas. No presente trabalho, a cultivar BRS 232 apresentou menor porcentagem de sementes danificadas e valores inferiores de condutividade elétrica (Tabela 1), o que justificaria o menor índice de velocidade de hidratação (Tabela 2).

Dentre outros fatores, a velocidade com que a água é absorvida pela semente depende da permeabilidade e integridade do tegumento (POPINIGIS, 1985). Na presente pesquisa, constatou-se correlação significativa entre os valores de espessura do parênquima lacunoso e de índice de velocidade de hidratação. As sementes da cultivar BRS 232, com maior espessura, tiveram menor índice de velocidade de hidratação e seriam menos sensíveis à absorção rápida de água. Com dados médios associados a um desempenho intermediário, as sementes das cultivares Embrapa 48 e BRS 245RR destacaram-se. Finalmente, constatou-se maior índice para a cultivar BRS 184. Houve equivalência de comportamento entre os materiais BRS 184 e BRS 245RR, que não diferiram entre si; portanto, o fato de que ambas apresentaram ranqueamento contrário quanto à espessura do parênquima e velocidade de absorção de água não deve ser considerado.

Os valores de teor de água das sementes de soja, relevantes na determinação da velocidade de hidratação, variaram de $6,54 \%$ a 7,03\%. Os teores apresentaramse baixos, provavelmente devido ao efeito do equilíbrio higroscópico com o ambiente (TOLEDO, 1969).

Quanto à evolução do processo de absorção de água, foi observada, conforme a Tabela 3 , referente às elevações percentuais do teor deágua em cada momento, que avelocidade de absorção de água mostrou diferenças entre os tratamentos na primeira e terceira hora. Na primeira hora, as diferenças entre os tratamentos foram mais acentuadas e permitiram discriminar níveis quanto à velocidade de absorção; 
menor teor percentual de água absorvido foi verificado em

de produção.

sementes da cultivar BRS 232, independentemente do local

TABELA 3. Acréscimos nos teores de água (\%) de semen- -tes de soja de diferentes cultivares e locais de produção em cada hora de hidratação.

\begin{tabular}{|c|c|c|c|c|c|c|c|c|c|}
\hline \multirow{2}{*}{$\begin{array}{c}\text { Localidade } \\
\mathrm{s}\end{array}$} & \multirow{2}{*}{ Tratamento } & \multicolumn{8}{|c|}{ Intervalo de hidratação (hora) } \\
\hline & & 1 & 2 & 3 & 4 & 5 & 6 & 7 & 8 \\
\hline \multirow{4}{*}{$\begin{array}{l}\text { Mauá da } \\
\text { Serra }\end{array}$} & Embrapa 48 & $1,167 \mathrm{bcd}^{1}$ & 1,041 & $0,933 \mathrm{ab}$ & 0,898 & 0,998 & 0,953 & 1,507 & 0,632 \\
\hline & BRS 184 & 1,215 bcde & 1,177 & $1,061 \mathrm{ab}$ & 1,056 & 1,055 & 0,984 & 0,847 & 0,833 \\
\hline & BRS 232 & $0,839 \mathrm{a}$ & 0,985 & $0,803 \mathrm{a}$ & 0,934 & 0,813 & 0,903 & 0,727 & 0,883 \\
\hline & BRS 245RR & $1,257 \mathrm{cde}$ & 1,167 & $1,252 \mathrm{ab}$ & 1,073 & 0,880 & 0,957 & 0,720 & 1,003 \\
\hline \multirow{5}{*}{ Londrina } & Embrapa 48 & $1,453 \mathrm{e}$ & 1,401 & $1,333 \mathrm{~b}$ & 1,257 & 0,916 & 0,925 & 0,816 & 0,863 \\
\hline & BRS 184 & 1,405 de & 1,146 & $1,145 \mathrm{ab}$ & 1,047 & 0,861 & 0,936 & 0,853 & 0,859 \\
\hline & BRS 232 & $1,002 \mathrm{ab}$ & 1,232 & $0,964 \mathrm{ab}$ & 1,288 & 0,896 & 0,972 & 0,848 & 1,142 \\
\hline & BRS 245RR & $1,448 \mathrm{e}$ & 1,299 & $0,983 \mathrm{ab}$ & 1,177 & 0,956 & 1,024 & 0,949 & 1,020 \\
\hline & Embrapa 48 & $1,256 \mathrm{cde}$ & 1,132 & $1,073 \mathrm{ab}$ & 1,044 & 1,015 & 0,852 & 1,806 & 0,769 \\
\hline \multirow{3}{*}{$\begin{array}{l}\text { Ponta } \\
\text { Grossa }\end{array}$} & BRS 184 & $1,145 \mathrm{bc}$ & 1,282 & $1,088 \mathrm{ab}$ & 1,018 & 1,030 & 1,178 & 1,503 & 0,679 \\
\hline & BRS 232 & $0,880 \mathrm{a}$ & 0,887 & $0,899 \mathrm{ab}$ & 0,784 & 0,813 & 0,901 & 0,633 & 0,812 \\
\hline & BRS 245RR & 1,216 bcde & 1,134 & $0,915 \mathrm{ab}$ & 1,119 & 1,131 & 1,116 & 0,889 & 1,014 \\
\hline \multirow{4}{*}{ Orlândia } & Embrapa 48 & 1,331 cde & 1,798 & $1,184 \mathrm{ab}$ & 1,213 & 1,084 & 0,966 & 1,546 & 0,930 \\
\hline & BRS 184 & 1,208 bcde & 1,249 & $1,132 \mathrm{ab}$ & 1,146 & 0,916 & 0,891 & 0,765 & 0,839 \\
\hline & BRS 232 & $0,891 \mathrm{a}$ & 0,965 & $0,866 \mathrm{ab}$ & 0,860 & 0,750 & 0,801 & 0,760 & 0,701 \\
\hline & BRS 245RR & $1,457 \mathrm{e}$ & 1,465 & $1,171 \mathrm{ab}$ & 1,152 & 1,059 & 0,979 & 0,869 & 0,948 \\
\hline \multicolumn{2}{|c|}{ C.V. $(\%)$} & 8,25 & 31,83 & 18,57 & 29,62 & 24,44 & 22,36 & 70,96 & 33,00 \\
\hline \multicolumn{2}{|c|}{$\mathrm{F}_{\text {calc }}$} & $17,147 * *$ & $1,303^{\mathrm{ns}}$ & $2,335^{*}$ & $0,821^{\mathrm{ns}}$ & $0,904^{\mathrm{ns}}$ & $0,973^{\text {ns }}$ & $1,051^{\mathrm{ns}}$ & $0,914^{\mathrm{ns}}$ \\
\hline
\end{tabular}

1 Médias seguidas da mesma letra na coluna não diferem estatisticamente entre si pelo teste de Tukey $(\mathrm{P} \leq 0,05)$

* e ** significativo a 5 e $1 \%$ de probabilidade, respectivamente; ns: não significativo

A análise da resposta das cultivares na terceira hora de hidratação permitiu constatar variações conforme os locais de produção; a resposta da cultivar BRS 232 em apresentar sementes com menores acréscimos no teor de água se manteve até a terceira hora, porém somente para as oriundas de Mauá da Serra. Da mesma maneira, sementes da cultivar Embrapa 48 que tiveram valor superior, na maioria das localidades, quanto ao acréscimo no teor de água na primeira hora, mantiveram idêntico comportamento quando oriundas de Londrina. Sementes da cultivar BRS 245RR, com acréscimos elevados no teor de água na primeira hora, não mais se diferenciaram das sementes das demais cultivares na terceira hora de absorção.

Mediante trabalho para avaliação de diferentes épocas de colheita de soja, Vieira et al. (1982) verificaram variações na quantidade de água absorvida nas seis primeiras horas de hidratação, decorrente do aumento de rachaduras e enrugamento das sementes. No presente trabalho foi constatada correlação entre o índice de velocidade de hidratação e o dano mecânico, que apontou as sementes da cultivar BRS 232 com menor porcentagem de sementes danificadas, justificativa dos resultados de menor absorção de água.

A espessura do tegumento também exerce importante papel na regulação do processo de absorção de água pelas sementes (McDONALD et al., 1988b). Apesar da ausência de diferença estatística entre os tratamentos para a espessura total do tecido de cobertura, foi possível a separação dos 
cultivares quanto à espessura do parênquima lacunoso, que possui de 6 a 8 camadas de células (SILVA, 2003), e, portanto, pode contribuir para reduzir a velocidade de absorção. Este fato é corroborado pela correlação significativa entre a espessura do parênquima e o índice de velocidade de hidratação de água pelas sementes, a 5\% de probabilidade. Neste sentido, menor e maior índices de velocidade de hidratação foram verificados em sementes das cultivares BRS 232 e BRS 245RR, respectivamente, em razão da maior e menor espessuras da referida camada de células, também de modo respectivo. Em um contexto físico, a água teria, em uma camada mais espessa de células, uma distância bem maior a percorrer (SILVA, 2003).

Nas Figuras 1A, 1B, 1C e 1D constam os ajustes dos dados de teor de água atingido pelas sementes de soja das diferentes cultivares, oriundas das localidades de Mauá da Serra, Londrina, Ponta Grossa e Orlândia, respectivamente, quando do processo de hidratação.
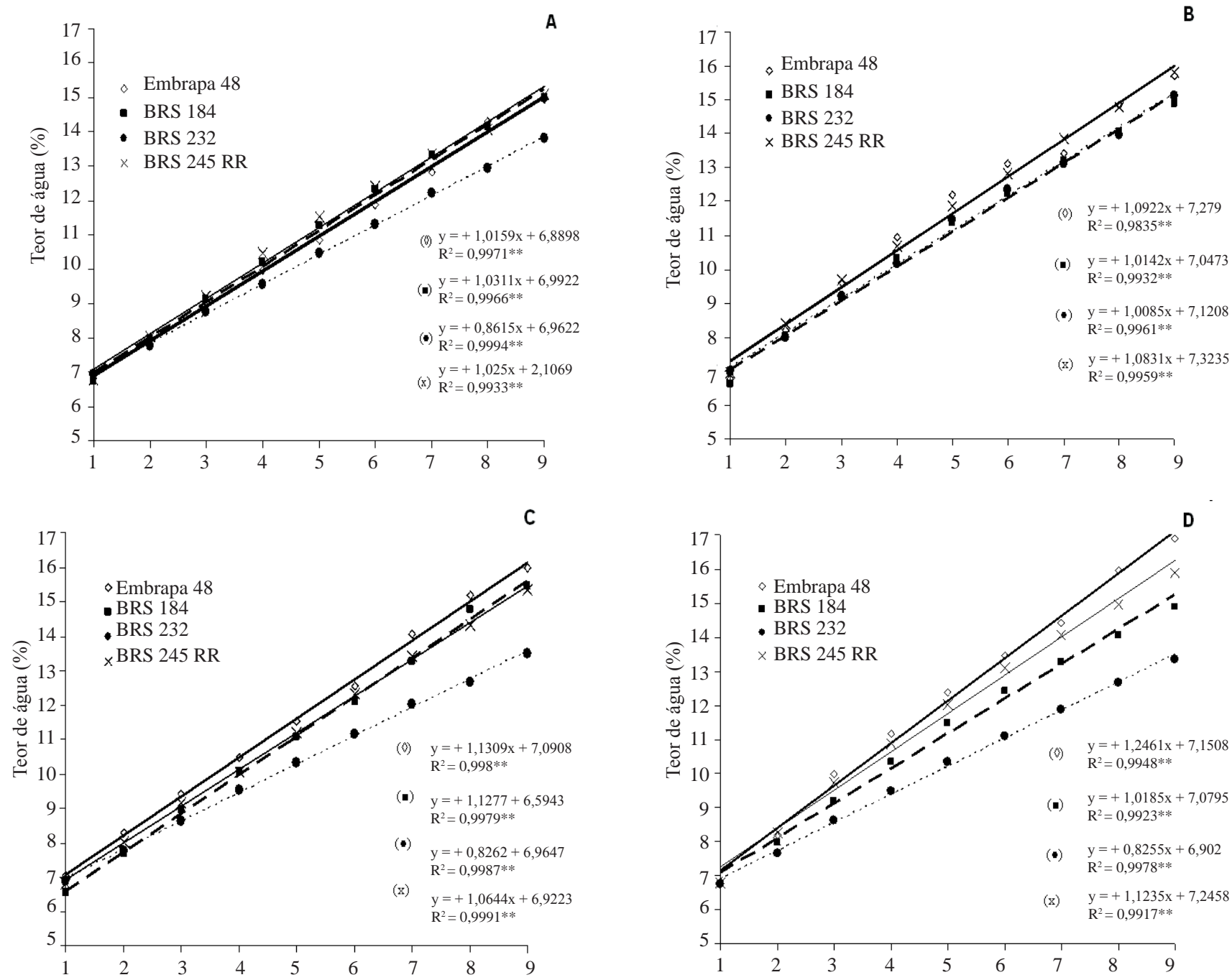

Tempo de hidratação (h)

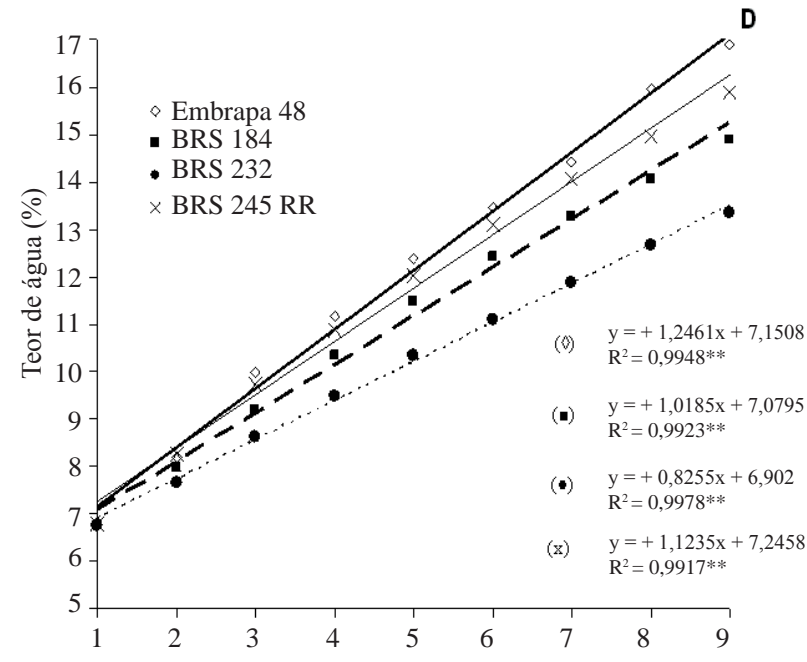

Tempo de hidratação (h)

FIGURA 1. Velocidade de absorção de água por sementes de soja de diferentes cultivares oriundas de Mauá da Serra (A), Londrina (B), Ponta Grossa (C) e Orlândia (D) em função do tempo de hidratação.

Diferentemente do verificado por Costa et al. (2002), a resposta das cultivares, quanto à capacidade de absorção de água pelas sementes em função do tempo foi linear, indicativa de acréscimos gradativos na quantidade de água 
absorvida. Santos et al. (2007), em sementes das cultivares Embrapa 48 e BRS 133, avaliadas até 24 horas de hidratação, também verificaram ajuste linear dos dados. Rodrigues et al. (2006), em estudo sobre tratamentos de pré-hidratação de sementes de soja, verificaram acréscimo acentuado no teor de água nas três primeiras horas; a partir de seis horas houve, praticamente, estabilização no acréscimo dos teores de água.

O padrão de absorção de água pelas sementes proposto por Labouriau (1983) e por Bewley e Black (1994) é trifásico; no entanto, este ajuste não foi observado provavelmente devido à metodologia utilizada, que permite que as sementes absorvam água até atingirem somente a fase II do processo, estabilizando-se neste momento. Rossetto et al. (1997), que constataram comportamento trifásico de absorção de água por sementes de soja, analisaram a marcha de absorção, sob diferentes tensões, até os períodos de 42 e 48 horas, quando se observou emissão da raiz primária; estes mesmos autores delimitaram o final da fase I após, um período de, aproximadamente, 12 horas, com as sementes atingindo teores de água entre 40 e $45 \%$, porém utilizando a técnica do substrato umedecido para avaliar o processo evolutivo de absorção de água.

\section{CONCLUSÕES}

A velocidade de hidratação de sementes de soja é afetada pela cultivar e local de produção.

A espessura do parênquima lacunoso do tegumento de sementes de soja relaciona-se significativamente com a velocidade de hidratação das sementes.

\section{AGRADECIMENTOS}

Ao Centro Nacional de Desenvolvimento Científico e Tecnológico $(\mathrm{CNPq})$, pela concessão da bolsa de estudos durante o curso de Mestrado.

\section{REFERÊNCIAS}

ALVAREZ, P.J.C. Relação entre o conteúdo de lignina no tegumento da semente de soja e sua relação ao dano mecânico. 1994. 43f. Dissertação (Mestrado em Agronomia) - Universidade Estadual de Londrina: Embrapa Soja: Instituto Agronômico do Paraná, Londrina.

ARANTES, H.A.G.; ROCHA, V.S.; SILVA, E.A.M.; SEDIYAMA, T. Espessura do tegumento, embebição em água e qualidade fisiológica da semente de soja (Glycine max
(L.) Merrill). Revista Ceres, v.41, n.234, p.126-132, 1994.

BECKERT, O.P.; MIGUEL, M.H.; MARCOS FILHO, J. Absorção de água e potencial fisiológico em sementes de soja de diferentes tamanhos. Scientia Agricola, v.57, n.4, p.671-675, 2000.

BEWLEY, J.D.; BLACK, M. Seeds: physiology of development and germination. New York: Plenum Press, 1994. 445p.

BRASIL. Ministério da Agricultura e da Reforma Agrária. Regras para análise de sementes. Brasília, DF: SNDA/ DNDV/CLAV, 1992. 365p.

CAVINESS, C.E.; SIMPSON, A.M.Jr. Influence of variety and location on seed coat thickness of mature soybean seed.

Proceedings of the Association of Seed Analysts, v.64, p.102-108, 1974.

COSTA, J.A.; PIRES, J.L.F.; THOMAS, A.L.; ALBERTON, M. Variedades de soja diferem na velocidade e capacidade de absorver água. Scientia Agraria, v.3, n.1-2, p.91-96, 2002.

COSTA, N.P.; PEREIRA, L.A.G.; FRANÇA-NETO, J. B.; HENNING, A.A.; KRZYZANOWSKI, F.C. Zoneamento ecológico do estado do Paraná para produção de sementes de cultivares precoces de soja. Revista Brasileira de Sementes, v.16, n.1, p.12-19, 1994.

DUANGPATRA, J.J. Some characteristics of the impermeable seed coat in soybean (Glycine max (L.) Merrill). 1976. 91f. Dissertation (PhD) - Mississipi State University, Starkville, 1976.

GERRITS, P.O. The application of glycol methacrylate in histotechnology: some fundamental principles. Netherlands: Department of Anatomy and Embryology State University Groningen, 1991. 80p.

GIURIZATTO, M.I.K.; SOUZA, L.C.F.; ROBAINA, A.D.; GONÇALVES, M.C. Efeito da época de colheita e da espessura do tegumento sobre a viabilidade e o vigor de sementes de soja. Ciência e Agrotecnologia, v.27, n.4, p.771-779, 2003.

KRZYZANOWSKI, F.C.; FRANÇA NETO, J.B.; COSTA, N.P. Teste do hipoclorito de sódio para semente de soja. Londrina: Embrapa Soja, 2004. 4p. (Embrapa Soja. Circular Técnica, 37).

LABOURIAU, L.G. Germinação das sementes. Washington: OEA, 1983. 174p. (Coleção de monografias científicas: biológicas, 24).

LOEFFLER, T.M.; TEKRONY, D.M.; EGLI, D.B. The bulk conductivity test as an indicator of soybean seed quality.

Journal of Seed Technology, v.12, n.1, p.37-53, 1988. 
MAGUIRE, J.D. Speed of germination aid in selection and evaluation for seedling emergence and vigor. Crop Science, v.2, n.2, p.176-77, 1962.

McDONALD, M.B.Jr.; VERTUCCI, C.W.; ROOS, E.C. Soybean seed imbibition: water absorption by seed parts. Crop Science, v.28, p.993-997, 1988a.

McDONALD, M.B.Jr.; VERTUCCI, C.W.; ROOS, E.C. Seed coat regulation of soybean imbibition. Crop Science, v.28, p.987-992, 1988b.

NAKAGAWA, J.; CAVARIANI, C.; MARTINS, C.C.; COIMBRA, R.A. Intensidade de dormência durante a maturação de sementes de mucuna-preta. Revista Brasileira de Sementes, v.29, n.1, p.165-170, 2007.

NATIONAL RESEARCH COUNCIL. Nutrient requirements of dairy cattle. 7ed. Washington: National Academy Press, 2001. 381p.

NOODÉN, L.D.; BLAKLEY, K.A.; GRZYBOWSKI, J.M. Control of seed coat thickness and permeability in soybean. Plant Physiology, v.79, p.543-545, 1985.

O’BRIEN,T.P.;FEDER, N.; McCULLY,M.E.Polychromatic staining of plant cell wall by toluidine blue. O Protoplasma, v.59, n.2, p.368-373, 1964.

PANOBIANCO, M.; VIEIRA, R.D.; KRZYZANOWSKI, F.C.; FRANÇA NETO, J.B. Electrical conductivity of soybean seed and correlation with seed coat lignin content. Seed Science and Technology, v.27, n.3, p.945-949, 1999.

PEREIRA, L.A.G.; ANDREWS, C.H. Comparison of nonwrinkled and wrinkled soybean seed coats by scanning electron microscopy. Seed Science and Technology, Zürich, v.13, p.853-860, 1985.

POPINIGIS, F. Fisiologia da semente. 2.ed. Brasília: AGIPLAN, 1985. 289p.

RODRIGUES, M.B.C.; VILLELA, F.A.; TILLMANN, M.A.A.; CARVALHO, R. Pré-hidratação em sementes de soja e eficiência do teste de condutividade elétrica. Revista Brasileira de Sementes, v.28, n.2, p.168-181, 2006.

ROSSETO, C.A.V.; NOVEMBRE, A.D.L.C.; MARCOS FILHO, J.; SILVA, W.R.; NAKAGAWA, J. Comportamento das sementes de soja durante a fase inicial do processo de germinação. Scientia Agricola, v.54, n.1/2, p.106-115, 1997.
SANTOS, E.L.; PÓLA, J.N.; BARROS, A.S.R.; PRETE, C.E.C. Qualidade fisiológica e composição química das sementes de soja com variação na cor do tegumento. Revista Brasileira de Sementes, v.29, n.1, p.20-26, 2007.

SILVA, M.A.D. Morfologia da testa e potencial fisiológico de sementes de soja. 2003. 84f. Tese (Doutorado em Produção e Tecnologia de Sementes) - Faculdade de Ciências Agrárias e Veterinárias, Universidade Estadual Paulista, Jaboticabal.

SOUZA, L.A.; ROSA, S.M.; MOSCHETA, I.S.; MOURÃO, K.S.M.; RODELLA, R.A.; ROCHA, D.C.; LOLIS, M.I.G.A. Morfologia e anatomia vegetal: técnicas e práticas. Ponta Grossa: UFPG, 2005. 194p.

SWANSON, B.G.; HUGHES, J.S.; RASMUSSEN, H. Seed microstructure: review of water imbibition in legumes. Food Microstructure, v.4, p.115-124, 1985.

TAVARES, D.Q.; MIRANDA, M.A.C.; UMINO, C.Y.; DIAS, G.M. Características estruturais do tegumento de sementes de linhagens de soja permeável e impermeável. Revista Brasileira de Botânica, v.10, p.147-153, 1987.

TOLEDO, F.F. Produção de sementes. Piracicaba: ESALQ, 1969. 59p. (Boletim didático, 11).

VAN SOEST, P.J.; WINE, R.H. Determination of lignin and cellulose in acid detergent fiber with permanganate. Journal of the Association of Official Agricultural Chemists, v.51, p.780-785, 1968.

VERTUCCI, C.W. The kinetics of seed imbibition. In: CROP SCIENCE SOCIETY OF AMERICA. Seed moisture. Madison, 1989. p.93-115. (CSSA. Special Publication, 14).

VIEIRA, R.D.; KRZYZANOWSKI, F.C. Teste de condutividade elétrica. In: KRZYZANOWSKI, F.C.; VIEIRA, R.D.; FRANÇA NETO, J.B. (Ed.). Vigor de sementes: conceitos e testes. Londrina: ABRATES, 1999. cap. 4, p.1-26.

VIEIRA, R.D.; PANOBIANCO, M.; LEMOS, L.B.; FORNASIERI FILHO, D. Efeito de genótipos de feijão e de soja sobre os resultados da condutividade elétrica de sementes. Revista Brasileira de Sementes, v.18, n.2, p.220224, 1996.

VIEIRA, R.D.; SEDIYAMA, T.; SILVA, R.F.; SEDIYAMA, C.S.; THIEBAUT, J.T.L. Efeito do retardamento da colheita sobre a qualidade de sementes de soja cv "UFV-2". Revista Brasileira de Sementes, v.4, n.2, p.9-22, 1982. 